diseases. It will also enable quick follow-up trials of combinations of antivirals and new treatments that have already shown evidence of activity. A different type of RCT might also become an option once more than one drug has shown efficacyeven efficacy in animal models. Then, patients could ethically be randomised to one investigational drug or another. No-one would get only standard care.

We accept that RCTs can generate strong evidence in ordinary circumstances; not, however, in the midst of the worst Ebola epidemic in history. The urgent need is to establish whether new investigational drugs offer survival benefits, and thus which, if any, should be recommended by WHO to save lives. We have innovative but proven trial designs for doing exactly that. We should be using them, rather than doggedly insisting on gold standards that were developed for different settings and purposes.

We declare no competing interests.

Clement Adebamowo,

Oumou Bah-Sow, Fred Binka,

Roberto Bruzzone, Arthur Caplan, Jean-François Delfraissy,

David Heymann, Peter Horby,

Pontiano Kaleebu,

Jean-Jacques Muyembe Tamfum,

*Piero Olliaro, Peter Piot,

Abdul Tejan-Cole, Oyewale Tomori,

Aissatou Toure, Els Torreele,

John Whitehead

piero.olliaro@ndm.ox.ac.uk

National Health Research Ethics Committee, Abuja, Nigeria (CA); Hôpital National Ignace Deen,

Conakry, Guinea (OB-S); University of Health and Allied Sciences, Ho, Ghana (FB); Hong Kong University-Pasteur Research Pole, School of Public Health, University of Hong Kong, Hong Kong, China (RB); New York University Langone Medical Center, New York, NY, USA (AC); Institut de Microbiologie et Maladies Infectieuses and INSERM, Paris, France (J-FD); Centre on Global Health Security, Chatham House, London, UK (DH); University of Oxford, Oxford, UK (PH); Medical Research Council, Uganda Virus Research Institute, Entebbe, Uganda (PK); Institut National de Recherche Biomedicale, Kinshasa, DR Congo (J-JMT); WHO, Geneva, Switzerland, and University of Oxford, Oxford, UK (PO); London School of Hygiene \& Tropical Medicine, London, UK (PP); Open Society Initiative for West Africa, Dakar, Senegal (AT-C); Nigerian
Academy of Science, Lagos, Nigeria (OT); Institut Pasteur Dakar, Dakar, Senegal (AT); Open Society Foundations, New York, NY, USA (ET); and Lancaster University, Lancaster, UK (JW)

1 Wellcome Trust. Ebola treatment trials to be fast-tracked in West Africa. Sept 23, 2014 http://www.wellcome.ac.uk/News/Mediaoffice/Press-releases/2014/WTP057419.htm (accessed Oct 9, 2014)

2 Joffe $S$. Evaluating novel therapies during the Ebola epidemic. JAMA 2014; 312: 1299-300.

\section{Ebola crisis: beliefs and behaviours warrant urgent attention}

Why is this 25th outbreak of Ebola in Africa presenting an impending geopolitical crisis? ${ }^{1}$

This is the first recognised outbreak in the west Africa region; the communities are not familiar with Ebola virus. Health beliefs, cultural practices, and human behaviour have combined to fan the dispersal of the disease. The concerns of the west African people, the myths, and conspiracies need to be heard and understood before communities will sufficiently engage to reduce further spread.

Civil unrest is a feature of this humanitarian disaster; suspicion and aggression towards health workers is widespread. ${ }^{2}$ The US and British military are indeed best resourced to build field hospitals; but their arrival is being seen on the ground, by some, as an invasion. These fears need to be addressed.

The socioeconomic collapse of the worst affected countries, already causing food insecurity, ${ }^{3}$ could exacerbate the destructive effects of Ebola, and create violence. The delivery of effective infection control measures and health care will be challenging under the threat of regional conflict. ${ }^{4}$

This humanitarian disaster will deepen in spite of committed efforts of governments, unless we can understand and address the human beliefs and behaviours fuelling this crisis.

We declare no competing interests.
*Claire Bayntun, Catherine Houlihan, John Edmunds

clairebayntun@doctors.org.uk

London School of Hygiene \& Tropical Medicine, London WC1E 7HT, UK

1 Martin-Moreno JM, Ricciardi W, Bjegovic-Mikanovic V, Maguire P, McKee M. Ebola: an open letter to European governments. Lancet 2014; 384: 1259

2 BBC. Ebola: Guineans riot in Nzerekore over disinfectant. Aug 29, 2014. http://www.bbc co.uk/news/world-africa-28984259 (accessed Oct 8, 2014).

3 World Food Programme. Guinea: Assistance to Food insecure Ebola Victims, Households and Communities in Forest Guinea. http://www. wfp.org/content/guinea-assistance-foodinsecure-ebola-victims-households-andcommunities-forest-guinea (accessed Oct 7, 2014).

4 International Crisis Group. Statement on Ebola and Conflict in West Africa. http://www. crisisgroup.org/en/publication-type/mediareleases/2014/africa/statement-on-ebola-andconflict-in-west-africa.aspx (accessed Sept 26, 2014)

\section{Antibiotic sutures against surgical site infections}

Markus Diener and colleagues (July 12, p 142) 1 might believe that the study protocol and sample size account for the conflicting findings in the PROUD trial ${ }^{1}$ (not showing a prophylactic effect of triclosancoated sutures against surgical site infection [SSI]) and for findings from smaller randomised controlled trials ${ }^{2-4}$ that show benefits for use in antibiotic sutures in prevention of SSI. However, the discrepancy might be more because of differences in baseline characteristics of participants.

Antimicrobial effects of triclosancoated sutures seem to depend on the length of skin incision, extent of wound contamination at operation, and concurrent diseases amenable to infections, such as diabetes. In a single-centre randomised trial, ${ }^{2}$ investigators reported triclosancoated sutures to be of slight benefit because they decreased the rate of SSIs after open colorectal surgery, but did not change infection 